\title{
Cost-Benefit Analysis of Sprinklers for Property Protection in New Zealand Parking Buildings
}

\author{
Yuguang Li, Stephenson\&Turner New Zealand Ltd, Auckland, New Zealand \\ Michael Spearpoint ${ }^{1}$, Department of Civil Engineering, University of Canterbury, \\ New Zealand.
}

\begin{abstract}
The provision of fire protection measures in parking buildings is an ongoing debate within the fire protection industry. This paper presents a cost-benefit analysis model for the installation of sprinklers for the property protection of these structures. An event tree analysis is used to evaluate vehicle fires in parking buildings drawing on data from New Zealand and international fire statistics. The event tree analysis is then applied to the cost-benefit model in which several scenarios relating to the type of parking building and the availability of sprinklers are considered. A case study is presented for a public parking building with a total floor area of $30,000 \mathrm{~m}^{2}$ and the most critical factors in determining the cost-benefit ratio are identified using a MonteCarlo sensitivity analysis. Using the cost-benefit model and from a building owner's point of view it is found that an economical automatic sprinkler system does not justify itself in a parking building.
\end{abstract}

\footnotetext{
${ }^{1}$ Corresponding author.
} 


\section{INTRODUCTION}

\section{Background}

The effects of fire in parking buildings and the necessary fire protection measures are recurring topics of discussion amongst the fire protection engineering community. For example, there is debate over the appropriateness of sprinkler provision and whether smoke extraction is required either by natural or mechanical means. Questions are also posed regarding whether such systems are necessary for the different types of parking structure commonly found in use and what is their impact on life and property safety.

The topic of the usefulness of sprinkler provision in a parking building attracts some specific discussion. One opinion considers the frequency of fire as sufficiently low and/or casts doubt on the effect of the sprinklers controlling the fire spread. The other opinion proposes that the sprinklers can control the fire development, providing tenable conditions for the building occupants and fire-fighters and giving a level of protection for the property.

An assessment of the risks posed by vehicle fires in parking structures is appropriate in order to determine what fire safety measures might be necessary. Li [1] investigated vehicle fires in New Zealand parking buildings over an 8 year period and used the results to develop the cost-benefit model described in this paper. Furthermore, as a result of Li's work, a discussion regarding the occurrence and severity of vehicle fires is presented elsewhere [2].

In this paper parking buildings are considered to be those structures that are used for the parking of multiple motor vehicles and do not include individual private garages, vehicle repairers, sales showrooms etc. In general parking buildings can be either one of two types: private or public. The private type is generally for people specifically entitled to park in the building, whereas the public type is for the use of any member of the community. Typically, vehicles in these buildings are private passenger cars or small utility trucks although other larger vehicles may also be occasionally present. The parking building can be either single level or a multi-storied structure and either be a standalone building or a structure adjacent to or above/below another occupancy. 
In the analysis presented in this paper it is assumed that a parking structure adjoining another occupancy is fire separated from that occupancy as is typically the case. Steel and concrete are the most commonly used materials for parking building construction and it is likely that structural collapse will not occur as a result of a vehicle fire, as demonstrated by a review of various vehicle fire experiments that have been conducted in parking structures [1].

\section{Code requirements}

The fire safety requirements, including structural fire ratings and provision of fire protection system such as sprinklers, vary between different building codes. In New Zealand, the mandatory provisions for building work are contained in the New Zealand Building Code (NZBC). In particular, the requirements for fire safety in car parks are laid out in clauses 6.10.3 to 6.10.6, in Part 6 (Control of Internal Fire and Smoke Spread) of Acceptable Solution C/AS1 [3]. According to C/AS1, sprinklers may not be required for an underground or closed parking building, provided other relevant fire safety requirements are satisfied. For an open parking building, which is cross-ventilated with at least two opposite sides, there is no specific requirement placed by the code in terms of the provision of fire protection systems.

Alternatively NFPA 88A [4] covers the construction and protection of both open and enclosed parking structures. Automatic sprinkler systems are not required for open parking structures. A parking structure not meeting the classification of an open parking structure is considered enclosed. In enclosed parking structures located within or immediately below another occupancy, either a sprinkler system or a fire detection system combined with a mechanical ventilation system is required. However automatic sprinkler systems are required in basement and underground parking structures with ceiling less than $2 \mathrm{ft}(0.61 \mathrm{~m})$ above grade. Automatic sprinkler systems are also required in enclosed parking structures with non-combustible or limited-combustible exterior structural materials, and entirely or partially wood interior structural members (referred to as Type III or IV construction) over $50 \mathrm{ft}$ (15.2 $\mathrm{m})$ in height. 


\section{EVENT TREE ANALYSIS}

\section{Event tree construction}

Event trees provide a model for identifying and quantifying several possible outcomes following an initiating event [5]. Two event trees are established for non-sprinklered and sprinklered parking buildings respectively where the initiating event is the annual probability of a vehicle fire in a parking building. The pathways for the vehicle fires in parking buildings are identified as:

- Building type - private or public,

- Fire cause - deliberate or accidental,

- Fire spread - contained in one vehicle or spread to others,

- Number of vehicles involved - one, two and three or more vehicles.

\section{Vehicle Fire Frequency per Vehicle Visit}

The primary purpose of the parking building is for the temporary storage of vehicles. The number of vehicles using a parking building affects the fire frequency, based on the assumption that the ignition probability for each vehicle visiting the parking building is the same. Chandler and Shipp [6] suggest that the occurrence of an accidental vehicle fire is not time related if the vehicle engine has been on or off for more than 20 minutes. Hence it is appropriate to relate the fire frequency to the number of vehicle visits to a parking building rather than the duration that vehicles spend in the building.

The concept of annual usage ratio is proposed where this is defined as annual vehicle visits to a particular parking building divided by total number of parking spaces in the parking building. The annual usage ratio represents the annual vehicle turnover rate in a particular parking building and also expresses the annual average number of vehicle visits to one parking space in the building. Parking building operators in New Zealand generally keep the yearly record of total vehicle visits into their parking buildings but the information is not easily accessible for reasons of commercial sensitivity. To obtain an estimate of likely annual usage ratios it was found that the number of car parking visits to Christchurch City Council's public parking buildings was 1,115,000 a year in 2003 [7]. The number of the parking bays in these buildings was 3,164 
therefore the average annual usage ratio or turnover ratio is $1,115,000$ visits year $^{-1} /$ 3,164 (bays) $\approx 350$ visits per year.

The product of the annual usage ratio and total number of parking spaces in New Zealand yields the number of total vehicle visits. It is estimated that there are 200,000 parking spaces in the whole of New Zealand. This value was obtained from data for the number of parking spaces in parking buildings and registered vehicles for two major New Zealand cities [1]. The total annual vehicle visits to New Zealand parking buildings can hence be estimated as 200,000 (spaces) $\times 350$ visits per year $=$ $70,000,000$ visits per year

Using data from New Zealand Fire Service Fire Incident Reporting System (FIRS) [8], the number of fire incidents involving vehicles in New Zealand parking buildings from 1995 to 2003 was 96 or on average 12 per year [2]. The frequency of vehicle fires in parking buildings for each vehicle visit is thus 12 year $^{-1} / 70,000,000$ visits year $^{-1}=1.71 \times 10^{-7}$ visit $^{-1}$

\section{Vehicle Fires in Non-Sprinklered Parking Buildings}

The vehicle fire frequency of $1.71 \times 10^{-7}$ visit $^{-1}$ was used for the initiating event in the event tree for vehicle fires in a non-sprinklered parking building. The completed event tree is shown in Figure 1 where the pathway probabilities were based on an analysis of the New Zealand Fire Service FIRS statistics. The performance of the fire protection system such as sprinklers was not available in the statistical data and it was conservatively assumed that the effect of any sprinklers on the fire occurrences can be ignored. Hence the probabilities shown in the event tree in Figure 1 are considered for the situation of non-sprinklered parking building. The consequential probability is the vehicle fire frequency per vehicle visit in any non-sprinklered parking building for each scenario as defined by each branch. These probabilities are shown at the end of the 12 branches of the event tree. 


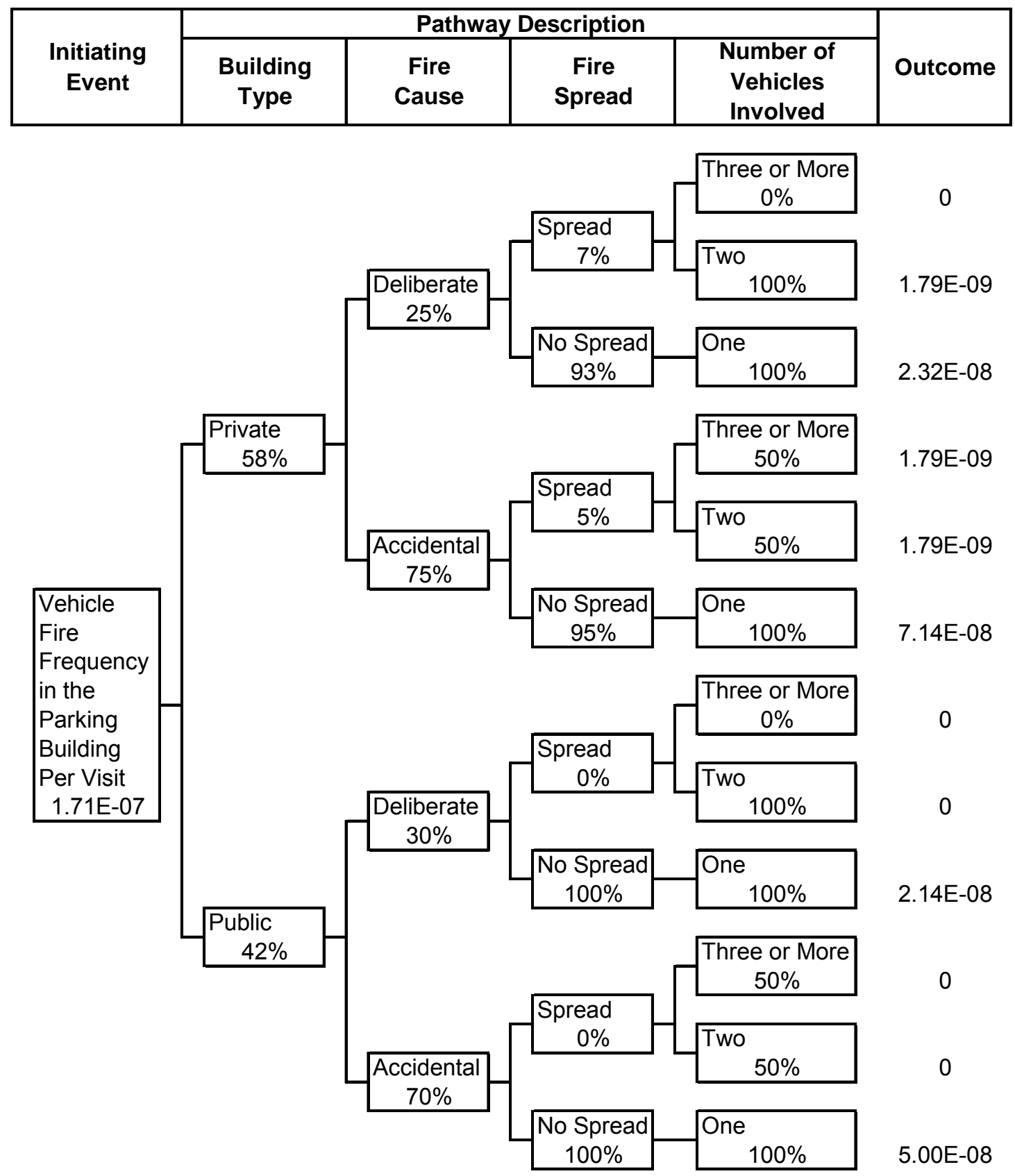

Figure 1: Event tree for vehicle fire incidents in non-sprinklered parking buildings.

\section{Vehicle Fires in Sprinklered Parking Buildings}

Generally, the operation of sprinklers can cool the environment and control the fire spread, thus protecting the building. For the situation in a parking structure various Australian fire tests, such as described in Bennetts et al. [9] and BHP [10], showed that sprinkler activation can confine the fire within the test car, hence preventing the vehicle fire from further development in the structure. A similar outcome is also 
suggested by Schleich et al. [11]. It is therefore assumed here that the activation of the sprinkler system in the event of a vehicle fire can constrain the fire within the originally ignited vehicle and protect the building from the fire damage. Effectively this also means that there will be no vehicle fire spread in a sprinklered parking building.

The event tree for vehicle fires in sprinklered parking buildings was constructed as a modified form of the event tree for non-sprinklered parking building. Marryatt [12] found that the success rate of automatic sprinkler systems was more than $99 \%$ during 100-year period from 1886 to 1986 in Australia and New Zealand. The sprinkler system success probability was therefore assumed to be an optimal $100 \%$. Based on this assumption, the probability for each branch of "Spread" in the pathway of "Fire Spread" is $0 \%$. The probability for each branch of "No Spread" in the same pathway is therefore $100 \%$. The probabilities for other branches remain the same as those in Figure 1.

\section{COST-BENEFIT ANALYSIS OF SPRINKLER PROVISION}

\section{Analysis by Cost-Benefit Ratio Method}

The concept of cost-benefit analysis (CBA) can be used to determine what the financial advantage would have been if the cost for a proposed safety measure had been put into a comparatively risky investment. The criterion of cost-benefit ratio is commonly used for the comparison of the alternative investment projects in which the financial equivalent benefit is divided by the financial equivalent cost to yield the cost-benefit ratio. This measure is used in this paper for the CBA of provision of sprinklers in New Zealand parking buildings.

The benefit from sprinklers is represented by the annual avoidance of cost that could have incurred due to vehicle fires in a non-sprinklered parking building, had sprinklers not been installed. The financial equivalent benefit is the present worth of the annual cost avoidance of fire damage by installing the sprinkler system. This present worth is expressed as the product of annual cost avoidance and the series present worth factor, which converts the annual cost avoidance to present worth based 
on a certain discount rate. The financial equivalent cost is the initial cost of the sprinkler system installation. The cost-benefit ratio, denoted as $\mathrm{B} / \mathrm{C}$, can then be expressed as [13]:

$\mathrm{B} / \mathrm{C}=\frac{\text { Annual Cost Avoidance } \times \text { Series Present Worth Factor }}{\text { Initial Cost }}$

When the cost-benefit ratio $(\mathrm{B} / \mathrm{C})$ is greater than unity, it indicates that the benefit is greater than the cost. Alternatively it means that an investment higher than the initial cost of sprinklers is required to achieve the return equivalent to the benefit (annual cost avoidance) from sprinklers based on a certain discount rate. Thus, the installation of the sprinkler system in a parking building is economically acceptable. Conversely, if the cost-benefit ratio is less than unity, the provision of sprinklers is considered as economically unacceptable.

In this paper, the quantification of vehicle fire risks was envisaged as the product of the frequency with which a fire occurs and the damage this fire causes. The annual cost avoidance of vehicle fire damage by sprinklers in the parking building can be written as:

\begin{tabular}{|c|c|c|c|c|}
\hline & & $\begin{array}{r}\text { Annualised } \\
\text { non-sprink } \\
\text { parking bui }\end{array}$ & $\begin{array}{c}\text { Reduced } \\
\text { annualised risk } \\
\text { in sprinklered } \\
\text { parking building }\end{array}$ & $\begin{array}{l}\text { Annual } \\
\text { maintenance } \\
\text { cost of } \\
\text { sprinklers }\end{array}$ \\
\hline & & dollar / year & (dollar / year) & (dollar / year) \\
\hline
\end{tabular}

\section{Scenarios}

A total of four scenarios were considered for the CBA of provision of sprinklers in parking buildings, according to the availability of the existing sprinkler system and the type of the parking building (Table 1). 


\begin{tabular}{|l|c|c|c|c|}
\hline Scenario No. & Scenario 1 & Scenario 2 & Scenario 3 & Scenario 4 \\
\hline $\begin{array}{l}\text { Extension from } \\
\text { existing sprinklers }\end{array}$ & \multicolumn{2}{|c|}{ Available } & \multicolumn{2}{|c|}{ Not-Available } \\
\hline $\begin{array}{l}\text { Type of parking } \\
\text { building }\end{array}$ & Private & Public & Private & Public \\
\hline
\end{tabular}

Table 1. Four scenarios considered in CBA of sprinkler provision in parking buildings.

The sprinkler costs are related to the availability of extending from an existing sprinkler system. The category of 'Available' would include the sprinkler system for parking building in or adjoining a building already protected by sprinklers; whereas the category of 'Not Available' would involve the system for a standalone parking building.

Equations for obtaining the cost-benefit ratios for the installation of sprinklers systems in parking buildings have been developed by $\mathrm{Li}$ [1]. For the sprinkler system which can be extended from an existing installation, the cost-benefit ratio can be written as:

$\mathrm{B} / \mathrm{C}=\frac{\left(\sum(f \times n)-f_{s} \times p\right) \times D \times R-M_{m}}{I_{m}} \times(P / A, i, N)$

For the sprinkler system which cannot be extended from an existing installation, the cost-benefit ratio can be written as:

$\mathrm{B} / \mathrm{C}=\frac{\left[\left(\sum(f \times n)-f_{s} \times p\right) \times D \times R-M_{m}\right] \times A-M_{F}}{I_{F}+I_{m} \times A} \times(P / A, i, N)$ 


\begin{tabular}{|c|c|c|c|c|c|}
\hline \multirow{4}{*}{ Parameter } & \multirow{4}{*}{ Unit } & \multicolumn{4}{|c|}{ Scenarios } \\
\hline & & Scenario 1 & Scenario 2 & Scenario 3 & Scenario 4 \\
\hline & & \multicolumn{2}{|c|}{$\begin{array}{c}\text { Available } \\
{[\text { Equation (3)] }}\end{array}$} & \multicolumn{2}{|c|}{$\begin{array}{l}\text { Not available } \\
{[\text { Equation (4)] }}\end{array}$} \\
\hline & & Private & Public & Private & Public \\
\hline$\sum(f \times n)$ & visit $^{-1}$ & $1.09 \times 10^{-7}$ & $7.14 \times 10^{-8}$ & $1.09 \times 10^{-7}$ & $7.14 \times 10^{-8}$ \\
\hline$f_{s}$ & visit $^{-1}$ & $1.00 \times 10^{-7}$ & $7.14 \times 10^{-8}$ & $1.00 \times 10^{-7}$ & $7.14 \times 10^{-8}$ \\
\hline$D$ & dollar $/ \mathrm{m}^{2}$ & 3870 & 3870 & 3870 & 3870 \\
\hline$p$ & $\%$ & $15 \%$ & $15 \%$ & $15 \%$ & $15 \%$ \\
\hline$M_{F}$ & dollar/year & 0 & 0 & 750 & 750 \\
\hline$M_{m}$ & $\begin{array}{l}\text { dollar/ } \\
\text { (m²year) }\end{array}$ & 0.025 & 0.025 & 0.025 & 0.025 \\
\hline$I_{F}$ & dollar & 0 & 0 & 20,000 & 20,000 \\
\hline$I_{m}$ & dollar/m $\mathrm{m}^{2}$ & 12 & 12 & 12 & 12 \\
\hline$(P / A, i, N)$ & - & 9.9148 & 9.9148 & 9.9148 & 9.9148 \\
\hline$i$ & $\%$ & $10 \%$ & $10 \%$ & $10 \%$ & $10 \%$ \\
\hline$N$ & year & 50 & 50 & 50 & 50 \\
\hline$R$ & visit/year & variable & variable & variable & variable \\
\hline$A$ & $\mathrm{~m}^{2}$ & - & - & variable & variable \\
\hline
\end{tabular}

- Not applicable.

Table 2: Parameter summary of four scenarios considered in CBA.

All the parameters in Equation (3) and Equation (4) are summarised in Table 2 and detailed later in this paper for all four scenarios considered. For Scenario 3 and 4 where the extension from existing sprinklers is not available, annual usage ratio $R$ and total floor area of parking building $A$ are variables. For Scenario 1 and 2 where the extension from existing sprinklers is available, the annual usage ratio $R$ is the only variable in the analysis since the total area term cancels through.

\section{Determination of Relevant Parameters}

\section{Non-Sprinklered Fire Frequency}

According to the level of the fire spread between parked vehicles or the number of vehicles involved due to a single ignition, vehicle fire risks in a non-sprinklered parking building can be classified into three fire spread scenarios, which are:

- Single vehicle involved 
- Two vehicles involved

- Three or more vehicles involved

The fire frequency per vehicle visit for each fire spread scenario $f$ is obtained from the event tree for vehicle fires in a non-sprinklered parking building as shown in Figure 1, by summing the frequencies for each fire spread scenario.

\section{Number of Vehicles Involved}

To correspond to the fire spread scenarios, there are three values for the number of vehicles involved $n$, which are 1, 2 and 4 using the statistics obtained from the New Zealand Fire Service FIRS database. For the scenario of "three or more vehicles involved", a value of 4 was used as it is the worst case of fire spread according to FIRS database.

\section{Sprinklered Fire Frequency}

The fire frequency, for both private and public sprinklered parking buildings, is based on the event tree for vehicle fires in sprinklered parking building. Similar to the nonsprinklered situation, these fire frequencies were obtained by summing the frequencies on relevant branches of the event tree for both private and public parking buildings. There is no fire spread in a sprinklered parking building as discussed earlier.

\section{Unit Fire Damage}

The unit fire damage is used to quantify the fire damage to the structure caused by vehicle fires and expressed in monetary value per unit area. Financial information for fire damage was not available for New Zealand parking buildings during the analysis and instead the fire damage reported in a 1972 US study by Harris [14] was used to determine the unit fire damage $D$ in non-sprinklered parking buildings.

The mean value from the distribution of the fire damage reported by Harris represents the expected value of property damage caused by a single vehicle fire in parking buildings. This figure is inflated to the current monetary value using the American 
Producer Price Index (PPI) before being converted to New Zealand currency to obtain the unit fire damage in New Zealand dollars. For a parking building, the average floor area per one parking space in this building is defined as the Efficiency [15]. As of 2000, the goal of most parking building designs in the US was to achieve an Efficiency of 28 to $30 \mathrm{~m}^{2} /$ space ( 300 to $325 \mathrm{ft}^{2} /$ space). Using an Efficiency value of $29 \mathrm{~m}^{2}$ per space and assuming a fire is restricted to the area of parking space, the unit fire damage by vehicle fire in a non-sprinklered parking building in New Zealand is determined as $\$ \mathrm{NZ} 3,871$ per $\mathrm{m}^{2}$.

\section{Fire Damage Reduction}

A vehicle fire controlled by sprinklers can still result in damage to the sprinkler protected parking building which can be expressed as a percentage $p$ of the unit fire damage to a non-sprinklered parking building. For a wide range of occupancies in the US, the average fire loss in a non-sprinklered building is approximately 4.5 times higher than that in an adequately sprinklered building [16]. Based on this value, the ratio between the fire loss in the sprinklered and non-sprinklered buildings is approximately 0.18 and a value of $15 \%$ was assumed for $p$ in this paper.

\section{Sprinkler Costs}

The costs for installing and maintaining sprinkler systems in New Zealand parking buildings were based on typical figures at the time of the analysis [17]. Two cost types are given, fixed and marginal. In particular, the fixed cost depends on the availability of the existing sprinkler system in a parking building. When a parking building is part of a building already protected by sprinklers, the additional fixed costs for installation and maintenance are generally negligible.

The initial costs for a sprinkler system in a parking building generally consist of a fixed cost for water supply to the system and a marginal cost for installing sprinklers. In this analysis the fixed initial cost did not include the expense of a pump, which is generally not required in parking building situations due to the relatively low flow rate demands by the system. The initial marginal cost was based on the installation of general use sprinkler heads with a maximum spacing of $12 \mathrm{~m}^{2}$ per head. The annual 
maintenance costs for a sprinkler system in a parking building are generally composed of fixed and marginal costs for inspection of the sprinkler system. The fixed cost includes the monthly testing and biennial inspection of the sprinkler system.

\section{Series Present Worth Factor}

The symbol $(P / A, i, N)$ is used to describe series present worth factor [18], which is a function of both discount rate $i$ and number of years $N$ considered in analysis. The discount rate is the annual percentage rate at which the present value of a future monetary value decreases through a certain period of time. It is used to convert all costs and benefits to the net present value or present worth, so that the comparison between alternative investment options can be performed. A discount rate of $10 \%$, which is used by the New Zealand Treasury for government projects [19] was selected for the CBA in this paper.

In this analysis, a service life of 50 years was assumed for general parking buildings in New Zealand. It was also believed that the sprinkler system would not have to be replaced during the whole life span of the building; hence the life of the sprinkler system installed in a parking building was assumed to be 50 years. The number of the years considered in the CBA was therefore 50 .

\section{Results}

\section{Sprinkler Extension Available}

The results from Equation (3) are shown in Figure 2, for Scenario 1 and Scenario 2 as defined in Table 1. In Scenario 1, the cost-benefit ratio reaches unity at the annual usage ratio of approximately 3,500. In Scenario 2, the cost-benefit ratio gets to unity at the annual usage ratio of around 5,000. These annual usage ratios are significantly greater than the annual usage ratio value of 350 discussed previously. The provision of sprinklers in the parking building would be considered economically unacceptable from the perspective of parking building owner. 


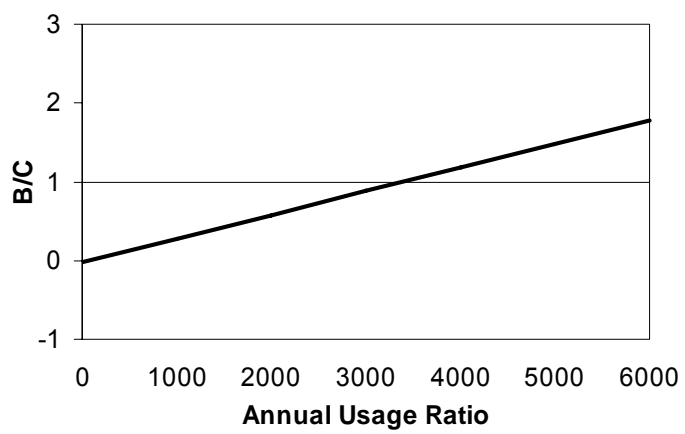

(a)

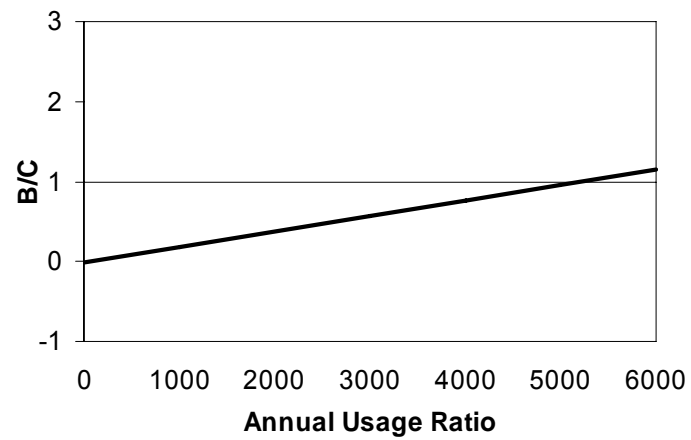

(b)

Figure 2. CBA results for sprinkler extension available: (a) Scenario 1 - Private parking building; (b) Scenario 2 - Public parking building.

\section{Sprinkler Extension Not Available}

The results from Equation (4) can be seen in Figure 3, for Scenario 3 and Scenario 4 as defined in Table 1. In Scenario 3, the cost-benefit ratio starts to reach unity for a parking building with a total floor area of more than $3,000 \mathrm{~m}^{2}$ and an annual usage ratio of around 6,000 . When the total floor area of a parking building gets to $50,000 \mathrm{~m}^{2}$, the cost-benefit ratio reaches unity at the annual usage ratio of approximately 3,500 . 


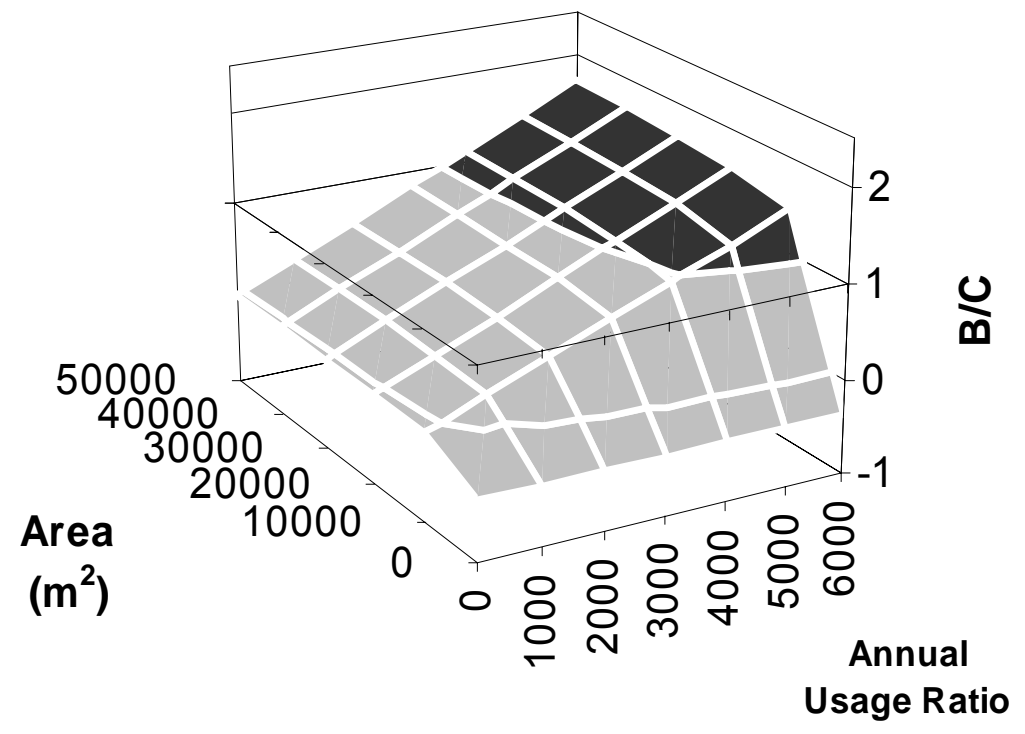

(a)

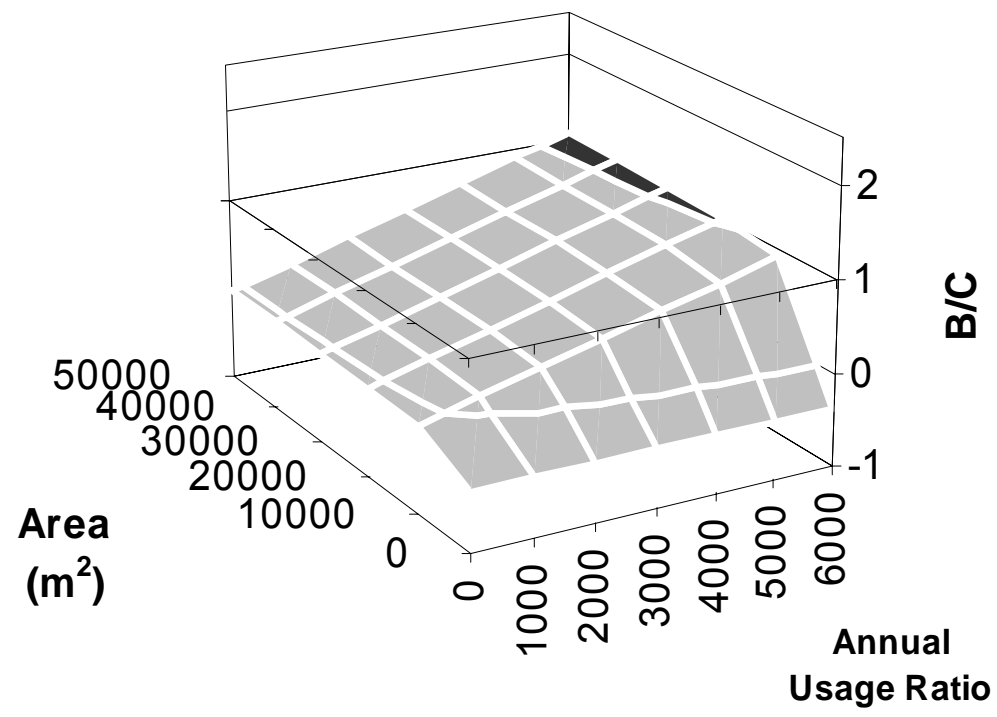

(b)

Figure 3. CBA results for sprinkler extension not available: (a) Scenario 3 Private parking building; (b) Scenario 4 - Public parking building.

In Scenario 4, the cost-benefit ratio starts to reach unity for the parking building with a total floor area of more than $20,000 \mathrm{~m}^{2}$ and an annual usage ratio of around 6,000. When the total floor area of a parking building gets to $50,000 \mathrm{~m}^{2}$, the cost-benefit ratio reaches unity at the annual usage ratio of approximately 5,500 .

Similar to Scenario 1 and 2, the annual usage ratios at which cost-benefit ratios reach unity in these two scenarios are considered relatively high. The provision of sprinklers 
in the parking building would again be considered economically unacceptable from the perspective of parking building owner.

\section{CASE STUDY USING MONTE-CARLO SIMULATION}

\section{The Parking Building in Consideration}

Based on the CBA model introduced earlier, further analysis was performed for a public parking building with an overall floor area of $30,000 \mathrm{~m}^{2}$ using Monte-Carlo simulation in @RISK software [20]. A parking building of this size can provide over 1,000 parking spaces with an Efficiency value of $29 \mathrm{~m}^{2} /$ space and is generally considered as a large size parking building in New Zealand. In terms of the extension from the existing sprinkler system, two scenarios were considered, which were 'Available' and 'Not Available'. These correspond to Scenario 2 and Scenario 4 as defined in Table 1. For Scenario 2 where the extension from an existing system is available, the total floor area $A$ is not relevant in the analysis as discussed previously.

\section{Simulation Inputs}

For each input in the simulation, Table 3 shows the probability distribution type with relevant statistical parameters such as minimum, mean (or expected value), maximum and standard deviation. These inputs are those appearing in Equation (3) and Equation (4); the probability distribution was defined in @ RISK program for each input. Scenario 4 (sprinkler extension not available) has two more inputs than Scenario 2 (sprinkler extension available). These two inputs are annual fixed maintenance cost $M_{F}$ and fixed initial cost $I_{F}$ for sprinklers.

Unit fire damage $D$ is represented by a trianglar distribution, which is also used to fit the historical fire damage from the 1972 US study [14]. The values of minimum and maximum are obtained from the 1972 US data using the same method for deriving unit fire damage in the CBA. A lognormal distribution is used for annual usage ratio $R$ as it is assumed that the likelihoods of having extremely high value of $R$ are relatively low. Due to the lack of relevant published statistical data the type of probability distribution for other inputs is based on engineering judgement. The mean of each 
distribution is taken as the corresponding value in Table 2 for each input. The minimum and maximum for each distribution are also assumed values and for the normal distribution type, the standard deviation is taken as $10 \%$ of the mean value.

\begin{tabular}{|c|c|c|c|c|c|}
\hline \multirow[b]{2}{*}{ Input description } & \multicolumn{5}{|c|}{ Statistics } \\
\hline & $\begin{array}{c}\text { Distribution } \\
\text { type }\end{array}$ & Minimum & Mean & Maximum & $\begin{array}{l}\text { Standard } \\
\text { deviation }\end{array}$ \\
\hline \multicolumn{6}{|c|}{ For Scenario 2 (sprinkler extension available) and Scenario 4 (sprinkler extension not available) } \\
\hline Non-sprinklered $-\sum f \times n$ & Normal & 0 & $7.14 \times 10^{-8}$ & +indefinite & $7.14 \times 10^{-9}$ \\
\hline Sprinklered $-f_{s}$ & Normal & 0 & $7.14 \times 10^{-8}$ & +indefinite & $7.14 \times 10^{-9}$ \\
\hline Unit fire damage $-D$ & Triangle & 23 & 3870 & 11536 & - \\
\hline Reduction percentage $-p$ & Normal & 0.00 & 0.15 & 1.00 & 0.015 \\
\hline Annual marginal maint. $-M_{m}$ & Triangle & 0.020 & 0.025 & 0.030 & - \\
\hline Marginal initial $-I_{m}$ & Triangle & 10 & 12 & 14 & - \\
\hline Discount rate $-i$ & Triangle & 0.05 & 0.10 & 0.15 & - \\
\hline Annual usage ratio $-R$ & Lognormal & 0 & 350 & +indefinite & 350 \\
\hline \multicolumn{6}{|c|}{ For Scenario 4 (sprinkler extension not available) only } \\
\hline Annual fixed maint. $-M_{F}$ & Triangle & 500 & 750 & 1000 & - \\
\hline Fixed initial $-I_{F}$ & Triangle & 15000 & 20000 & 25000 & - \\
\hline
\end{tabular}

Table 3. Details of probability distributions for each @RISK input.

\section{Output Results}

The cost-benefit ratios $(\mathrm{B} / \mathrm{C})$ in Equation (3) and Equation (4) were identified as the outputs in @RISK program, for both scenarios which are extension from existing sprinklers Available (Scenario 2) and Not Available (Scenario 4). The distributions of output results from @RISK, as shown in Figure 4, are similar for both scenarios. The distribution type of 'Pearson5' fits both results according to goodness-of-fit tests in @ RISK. This appears to relate to the probability distribution of annual usage ratio $R$, which is a Lognormal type. The mean of cost-benefit ratio is 0.049 for the scenario of sprinkler extension available and 0.026 for the scenario of sprinkler extension not available. 


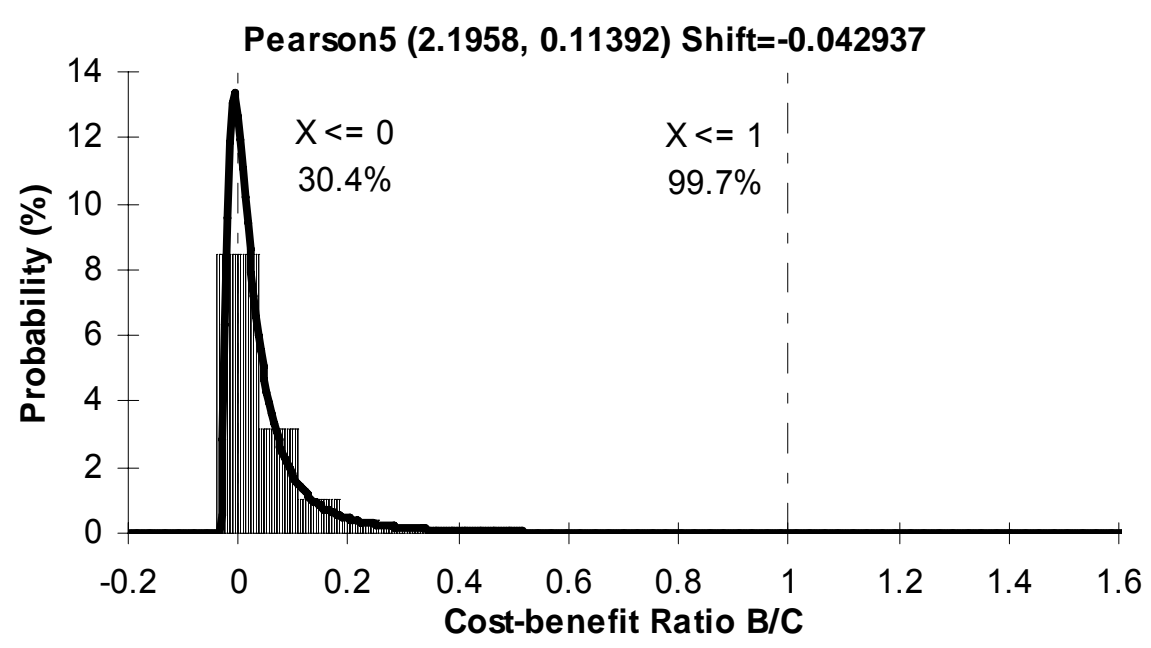

(a)

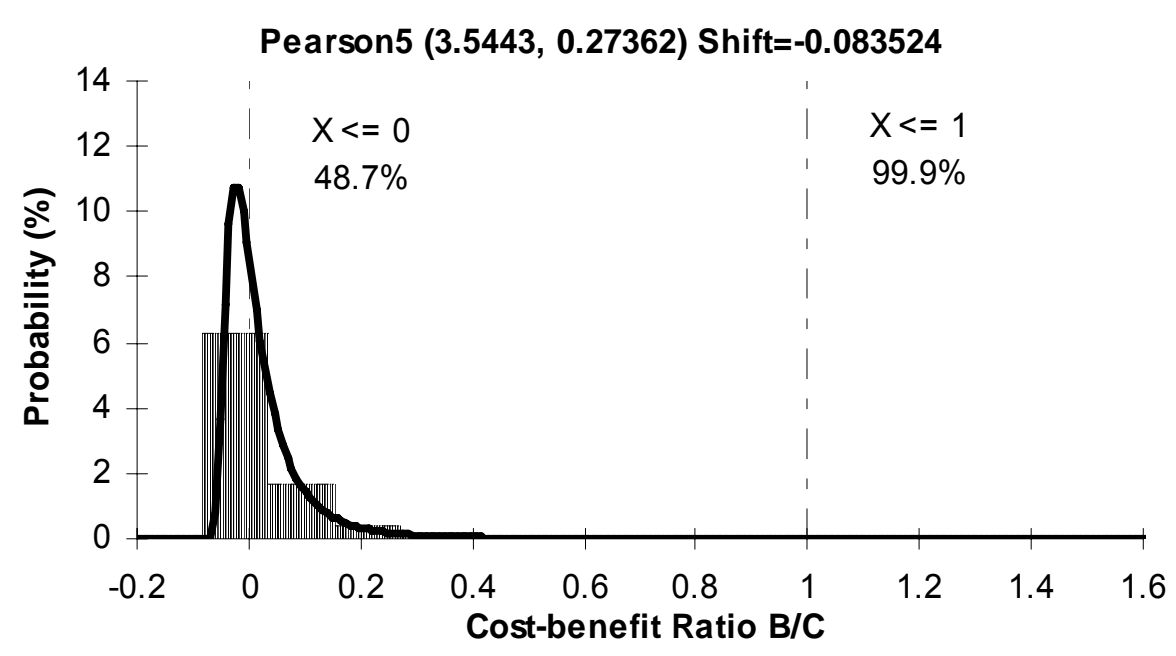

(b)

Figure 4. The distribution of cost-benefit ratio from @RISK for a public parking building (30,000 $\left.\mathrm{m}^{2}\right)$; (a) Sprinkler extension available; (b) Sprinkler extension not available.

Figure 4 also indicates that the cumulative probability of cost-benefit ratio exceeding the value of 1 is $0.3 \%$ for Scenario 2 and $0.1 \%$ for Scenario 4 . For both scenarios the provision of sprinklers for property protection would be considered economically unacceptable for this public parking building with a total floor area of $30,000 \mathrm{~m}^{2}$. 


\section{Sensitivity Analysis of Inputs}

The regression tornado graphs in Figure 5 show the regression sensitivity of each input for both scenarios. Each input is ranked according to how sensitive the costbenefit ratio is to the input distribution. The regression sensitivity results from (a) RISK show that annual usage ratio $R$ has the most influence on the output of costbenefit ratio, for both scenarios. For Scenario 2, the next three critical inputs by ranking are unit fire damage $D$, discount rate $i$, and non-sprinklered $\sum(f \times n)$. For Scenario 4 , the next three critical inputs by ranking are unit fire damage $D$, nonsprinklered $\sum(f \times n)$, and discount rate $i$.

In regression tornado graphs for both scenarios, there are three inputs having a positive impact on the output of cost-benefit ratio. Those inputs are annual usage ratio $R$, unit fire damage $D$, and $\sum f \times n$ for non-sprinklered parking buildings. 


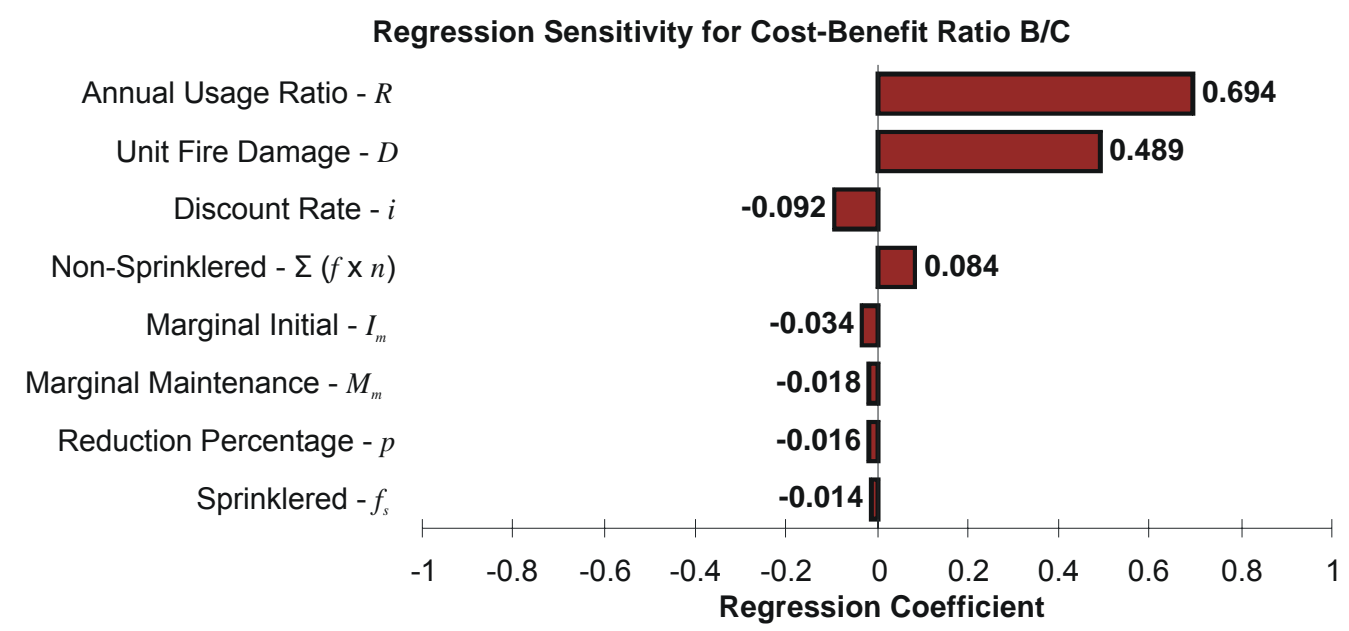

Sprinkler Extension Available (Scenario 2)

Regression Sensitivity for Cost-Benefit Ratio B/C

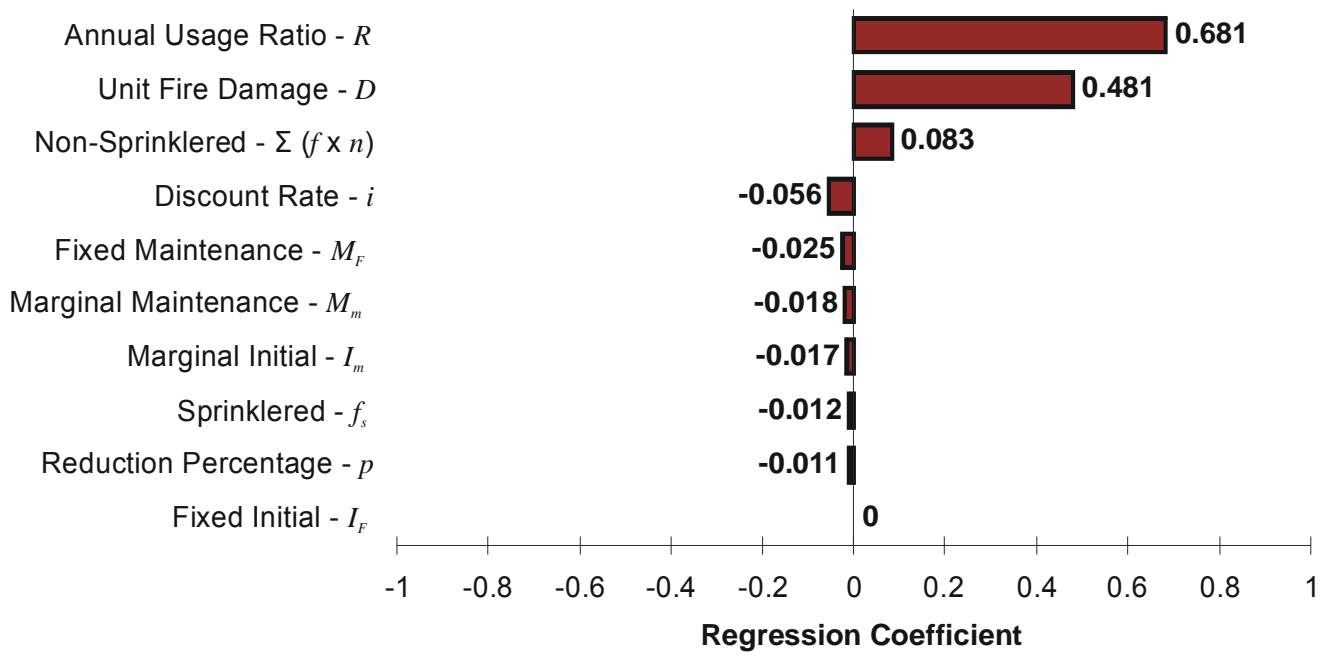

Sprinkler Extension Not Available (Scenario 4)

Figure 5. Ranking of inputs by regression sensitivity for both scenarios.

\section{DISCUSSION}

\section{Limitations of Cost-Benefit Analysis}

\section{Parameter sensitivity}

Clearly the outcome of the cost benefit analysis is only as good as the assumptions made and the data provided to the model. The sensitivity analysis revealed that the annual usage ratio and unit fire damage where the most critical variables in 
determining the economics of providing property protection to parking structures through the use of sprinklers. In both cases only a limited amount of data were identified in this study. Only a single estimate of a typical value for the annual usage ratio was available and the value of 350 year $^{-1}$ suggests that, on average, a space is only visited once per day. This value might be lower when compared to what might be obtained for say a busy parking building close to a shopping complex. More data for annual usage ratios is desirable to determine what range of values is reasonable for different types of parking building and thus give emphasis to the significance of the CBA model outcomes.

\section{Parking Density}

The prerequisite of the fire spread between vehicles is that vehicles in consideration are parked next to each other. When a vehicle catches fire and there are no neighbouring vehicles, the fire spread to other vehicles is not likely to happen. Therefore the density of vehicle parking in a non-sprinklered parking building would affect the probabilities of fire spread between vehicles. To simplify the event tree model, it is assumed that there are always vehicles adjacent to the one first ignited. As a result, constant probabilities were assigned to the pathway of "Fire Spread" in the event tree for a non-sprinklered parking building (Figure 1). Since the current model assumes a maximum potential for car-to-car fire spread due to neighbouring vehicles, it is likely that the model gives a higher benefit to sprinklers than where the probability of car-to-car fire spread is a function of parking density. It is therefore recommended that the variation of the parking density be incorporated into the event tree model in any future analysis.

\section{Additional financial factors}

The activation of sprinklers in the event of a vehicle fire can prevent the fire spread between the neighbouring vehicles and protect the building structure. Nevertheless damage to the burning vehicle is unavoidable because it is highly likely that vehicle involvement would already be significant before sprinkler activation and sprinklers will not be able to extinguish the fire inside a vehicle [1]. The exact details regarding the liability for the loss of the vehicle is not within the scope of this study and hence 
was not included in the CBA. However, it would be expected that the financial loss would be assumed by the vehicle owner or their insurance company rather than the parking building owner.

The interruption or loss of the business, particularly following a vehicle fire in a nonsprinklered parking building, could cause financial loss for the building owner for example through the loss of short stay parking fee income. On the other hand, the provision of sprinklers in the parking building might allow the trade-off in building design and reduction of the insurance premium cost, which would contribute to the benefit of sprinklers in the parking building. However the relevant commercially sensitive data were unavailable for the inclusion of these factors into this analysis. Although not considered in CBA, the interruption or loss of the business may not affect the analysis substantially. For a parking building with relative large capacity (total floor area) and high occupancy (annual usage ratio), the provision of sprinklers already becomes economically justified without considering the loss of business, as shown by the analysis. On the other hand, the loss of business probably does not have a significant impact on the analysis results for a parking building with large capacity and low usage, where the parking spaces not affected by the fire damage can be utilised in lieu of those fire damaged and requiring repair. The inclusion of the loss of business may affect the analysis results for a parking building of small capacity. Nevertheless, such parking buildings tend to be private type parking buildings where income may more likely be generated through long term parking arrangements and the loss of short stay fee income is not such a concern.

\section{Life Safety versus Property Protection}

The result from the current CBA agrees with the requirement placed by Acceptable Solution (C/AS1) in New Zealand Building Code where the provision of sprinklers is often non-mandatory. However it should be noted that the building code is concerned with life safety and not property safety protection. As with any fire in an occupied space there is potential for casualties and the risk involved would need to be included in a life safety cost-benefit analysis. 
There are only two minor burn injuries each year caused by vehicle fires in New Zealand parking buildings [2]. In the US, Harris [14] reported no injuries from 395 parking structure fires; while Denda [21] found eight injuries, which were reported as not directly fire related, from over 400 parking structure fires. Therefore because of the apparent rarity of injuries, the possible resulting financial loss in parking building fires could potentially be ignored and not included in a CBA. Furthermore, there were no fatalities reported from 1995 to 2003 in New Zealand parking building fires [2]. Similarly, several other studies $[14,21,22]$ have shown no instance of fatality in a parking structure fires. Consequently the financial loss from the death in parking building fires cannot be quantified and could not be considered statistically in a CBA. No studies on the potential life safety effects of vehicle fires in parking buildings were identified in the literature, hence future research is recommended to investigate this aspect.

\section{CONCLUSION}

The CBA presented in this paper is from the perspective of the owner of the parking building, which can be a stand-alone parking building or a building with some parts dedicated to vehicle parking. The parking building is assumed to be a separate firecell, when it adjoins the structure of other occupancies. Thus the fire and smoke can be confined within the parking building without spreading to the adjacent structures and vice versa.

Event tree analysis was carried out for vehicle fire risks in New Zealand parking buildings. The frequency of vehicle fires in New Zealand parking buildings was estimated to be $1.71 \times 10^{-7}$ per each vehicle visit. The CBA for the provision of sprinklers in a parking building was performed based on the New Zealand statistics and event tree analysis of vehicle fires in New Zealand parking buildings. The analysis indicated that an economical automatic sprinkler system generally does not justify itself, from the building owner's point of view for both private and public type buildings. The analysis does not consider the potential life safety benefits of a sprinkler system since input data to the CBA is unavailable. 
The sensitivity analysis of the CBA model for a public parking building with a total floor area of $30,000 \mathrm{~m}^{2}$ shows that the annual usage ratio is the most critical factor in the CBA. When applying the CBA methodologies presented in this paper for a particular parking building, one would need to obtain appropriate data such as annual usage ratio $R$, non-sprinklered $\sum(f \times n)$, and unit fire damage $D$ for the building under consideration, such that a more accurate result from cost-benefit ratio can be found.

\section{NOMENCLATURE}

$\sum(f \times n) \quad \sum$ (Fire frequency per vehicle visit in a non-sprinklered parking building for each fire spread scenario $\times$ Number of vehicles involved in fire)

$f_{s} \quad$ Fire frequency per vehicle visit in a sprinklered parking building

D Unit fire damage in a non-sprinklered parking building (NZ\$)

$p \quad$ Reduction percentage to allow reduced fire damage in a sprinklered parking building

$M_{F} \quad$ Annual fixed maintenance cost (NZ\$)

$M_{m} \quad$ Annual marginal maintenance cost per unit floor area (NZ\$)

$I_{F} \quad$ Fixed initial cost $(\mathrm{NZ} \$)$

$I_{m} \quad$ Marginal initial cost per unit floor area $(\mathrm{NZ} \$)$

$(P / A, i, N) \quad$ Series present worth factor

i Discount rate

$N \quad$ Number of years considered in CBA

$R \quad$ Annual usage ratio defined as annual vehicle visits divided by the number of parking spaces in a parking building

A Total floor area of the parking building considered in the analysis $\left(\mathrm{m}^{2}\right)$ 


\section{REFERENCES}

1. Y. Li. Assessment of Vehicle Fires in New Zealand Parking Buildings. Fire Engineering Research Report 04/2, Christchurch, New Zealand, 2004.

2. Y. Li, M. J. Spearpoint. Analysis of vehicle fire statistics in New Zealand parking buildings. Submitted to Fire Technology, 2004.

3. New Zealand Building Industry Authority and Standards Association of New Zealand. Approved Document for New Zealand Building Code: Fire Safety Clauses: C1, C2, C3, C4. Standards New Zealand, Wellington NZ, 2000.

4. National Fire Protection Association. NFPA 88A Standard for Parking Structures. 1998. National Fire Protection Association, 1998.

5. J. M. Watts, J. R. Hall. Introduction to Fire Risk Analysis. Section 5 / Chapter 1, (P. J. DiNenno, ed.) SFPE Handbook of Fire Protection Engineering ( $3^{\text {rd }}$ ed.), NFPA, Quincy, MA, 2002.

6. S. E. Chandler, M. P. Shipp. Channel Tunnel - A Statistical Study of the Fire Incidence in Road Vehicles. Fire Safety Engineering, 2 (3): 10-12, 1995.

7. Christchurch City Council. Parking Strategy for the Garden City. Christchurch City Council, Christchurch, New Zealand, 2003. Available online http://www.ccc.govt.nz/parkingstrategy/parkingstrategy.pdf.

8. New Zealand Fire Service. New Zealand Fire Service Fire Incident Reporting System Instruction \& Coding Manual: For Data Collected After 1 July 1995. Planning and Review Division National Headquarters, Wellington, NZ, 1995.

9. I. D. Bennetts, I. R. Thomas, D. Proe, R. Lewins. Fire Safety in Carparks. BHP Steel, Structural Steel Development Group, Melbourne, Vic, 1990. 
10. BHP. Fire and Unprotected Steel in Closed Carparks. BHP Melbourne Research Laboratories, Melbourne, 1987.

11. J. B. Schleich, L. G. Cajot, M. Pierre, M. Brasseur. Development of Design Rules for Steel Structures Subjected to Natural Fires in Closed Car Parks. European Commission, Luxembourg, 1999.

12. H. W. Marryatt. Fire: A Century of Automatic Sprinkler Protection in Australia and New Zealand 1886-1986. Australian Fire Protection Association in co-operation with National Fire Protection Association International and National Fire Sprinklers Association Inc. U.S.A, North Melbourne, Vic, Aust, 1988.

13. T. F. Barry. Risk-Informed, Performance-Based Industrial Fire Protection: An Alternative to Prescriptive Codes. 1st. Tennessee Valley Pub., Knoxville, Tenn., 2002.

14. L. M. Harris. Survey of Fire Experience in Automobile Parking Structures in the United States and Canada. Marketing Research Associates, Teaneck, NJ, 1972.

15. A. P. Chrest, M. S. Smith, S. Bhuyan, M. Iqbal, D. R. Monahan. Parking Structures: Planning, Design, Construction, Maintenance, and Repair. $3^{\text {rd }}$ edition. Chapman \& Hall, New York, 2000.

16. D. J. Rasbash, G. Ramachandran, B. Kandola, J. M. Watts, M. Law. Evaluation of Fire Safety. John Wiley \& Sons, Ltd, 2004.

17. C. Mak. Personal Communication, Tyco New Zealand Ltd. (Wormald), 2004.

18. J. M. Watts, R. E. Chapman. Engineering Economics. Section 5 / Chapter 7, (P. J. DiNenno, ed.) SFPE Handbook of Fire Protection Engineering ( $3^{\text {rd }} \mathrm{ed}$.), NFPA, Quincy, MA, 2002. 
19. L. Young. Determining the Discount Rate for Government Projects. The New Zealand Treasury, Wellington, Available online http://www.treasury.govt.nz/workingpapers/2002/twp02-21.pdf, 2002.

20. Palisade. @RISK - Risk Analysis and Simulation Add-In for Microsoft ${ }^{\circledR}$ Excel (Version 4.5), Palisade Corporation, 2002.

21. D. Denda. What About Parking Garage Fires. American Fire Journal, 45 (2): 22-25, 27, 1993.

22. Joyeux, D., Statistics in Car Parks. Report INC-01/91 - DJ. CTICM Department Incendie et Essais. Saint-Remy-Les-Chevreuse, France, 2001. 